\title{
Heterotic Classes and Utilization Patterns in Chinese Foxtail Millet [Setaria italica (L.) P. Beauv]
}

\author{
Zhengli Liu1 ${ }^{*}$, Guihua Bai',3, Dadong Zhang³, Chengsong Zhu3 ${ }^{3}$, Xiaoli Ren1, Suying Li1 \\ ${ }^{1}$ National Foxtail Millet Improvement Center, Institute of Millet Crops, Hebei Academy of Agricultural \& \\ Forestry Sciences, Shijiazhuang, China \\ ${ }^{2}$ USDA-ARS Hard Winter Wheat Genetics Research Unit, Manhattan, KS, USA \\ ${ }^{3}$ Department of Agronomy, Kansas State University, Manhattan, KS, USA \\ Email: *liuzhengli65@126.com
}

Received 14 October 2014; revised 31 October 2014; accepted 12 November 2014

Copyright (C) 2014 by authors and Scientific Research Publishing Inc.

This work is licensed under the Creative Commons Attribution International License (CC BY).

http://creativecommons.org/licenses/by/4.0/

(c) (i) Open Access

\begin{abstract}
Utilization of heterosis to develop hybrid cultivars can significantly increase yield of most crops including foxtail millet. However, previous foxtail millet hybrid cultivars have been largely developed from crosses between sterile lines and conventional varieties or between sterile lines and varieties that are geographically distent from the sterile lines. The research on classification of heterotic classes and determinetaion of heterotic patterns has not been reported, which results in uncertainty in selection of parents for crosses and delays progress in utilization of high yielding hybrids in large-scale commercial production. In this study, a core collection of 128 accessions from China was grouped into six classes using combined analyses of population structure, pedigree, and clustering. The classification was conducted based mainly on molecular clustering of genotypic data, also considered the population structure and mathematical clustering using phenotypic data, and was finally validated through pedigree analysis. According to the transgressive and superstandard heterosis for grain yield, plant height, panicle length, panicle diameter, single panicle weight, grain weight per panicle, and 1000-grain weight collected from an incomplete-diallel-cross experiment, we identified six superior heterosis patterns $(\mathrm{C2} / \mathrm{C1}, \mathrm{C2} / \mathrm{C4}, \mathrm{C2} / \mathrm{C5}, \mathrm{C2} / \mathrm{C6}$, $\mathrm{C1} / \mathrm{C5}$ and $\mathrm{C4} / \mathrm{C5}$ ) and four inferior heterosis patterns (C1/C3, C1/C4, C1/C6 and C4/C6), and explored their potential applications in millet hybrid breeding. This study laid a foundation for effective use of foxtail millet heterosis in improving millet hybrid yield.
\end{abstract}

\section{Keywords}

Foxtail Millet, Heterotic Classes, Heterotic Pattern, Molecular Clustering, Population Structure

\footnotetext{
${ }^{*}$ Corresponding author.
}

How to cite this paper: Liu, Z.L., Bai, G.H., Zhang, D.D., Zhu, C.S., Ren, X.L. and Li, S.Y. (2014) Heterotic Classes and Utilization Patterns in Chinese Foxtail Millet [Setaria italica (L.) P. Beauv]. Agricultural Sciences, 5, 1392-1406. 


\section{Analysis, Pedigree Analysis, Mathematic Clustering}

\section{Introduction}

Breeding hybrid cultivars using heterosis has been a critical strategy to increase grain yield in maize (Zea mays L.) [1] [2], sorghum (Sorghum bicolor L.) [3] [4], rice [5] and many other crop species. Utilization of heterosis in foxtail millet [Setaria italica (L.) P. Beauv.] also significantly improves millet yield [6].

The degree of heterosis in a hybrid depends on the genetic relationship of its parents. Due to lack of knowledge on heterotic classes and the genetic relationship among these classes, foxtail millet hybrid cultivars have been largely developed by crossing sterile lines to conventional cultivars or sterile lines to cultivars that are geographically distant from the sterile lines [7]. Geographically distent parents, however, are not necessary to be genetically distant from each other due to extensive exchange of germplasm among different ecological regions and intensive use of a few common parents such as Yugu 1, Qingdaolao, Zhaogu 1, Qinyuanmujizui and Moligu [8]-[11] in almost all Chinese hybrid breeding programs, which might be the major reason for current hybrid cultivars far from reaching its yield potential. Investigating heterotic classes and determining best heterotic class combinations, or heterotic patterns, can provide a guideline for effective use of heterosis in hybrid breeding, therefore, to further improve the level of hybrids' heterosis.

Foxtail millet is a minor crop. It is mainly cultivated in developing countries such as China and India. Basic research on the heterosis utilization in foxtail millet is far behind other cereal crops. There are only limited studies on classification and utilization of heterotic classes to predict heterotic hybrids in breeding. Study on pedigree evolution of foxtail millet cultivars revealed dynamic changes in pedigrees of mainstay cultivars from the northern China summer millet region released at different historic periods [8] [10]-[12]. However, some cultivars do not have pedigrees available or have incorrect pedigrees, and even when the accurate pedigree is available, different lines selected from the same cross may have different genetic makeups. Therefore, pedigree analysis alone cannot accurately classify current breeding materials into reasonable heterosis classes.

DNA marker provides the most accurate method for exploring genetic relationship among genotypes. Markers including amplified fragment length polymorphism, randomly amplified polymorphic DNA and simple sequence repeat (SSR) have been used in many studies on millet genetic diversity [13]-[17]. Only a few studies on millets reported use of SSR markers in cluster analysis [14] [16] [17] and population structure analysis [9]. Reports on heterotic classes and heterotic patterns that can guide effective use of heterotic millet resources have not been documented.

Studies on heterotic classes and patterns were reported in maize [18]-[22], rice [23]-[28] and Triticeae crops [29]-[32]. These studies classified heterotic classes or established heterotic patterns using molecular clustering, mathematical clustering, or pedigree analysis. However, using only a single analytic method in each of these studies might not be able to reflect the actual heterotic classes. Among different analytic methods used for heterotic classification, marker data are usually used to construct molecular clusters, but it is difficult to set an objective genetic distance threshold for class separation in a clustering tree. Population structure analysis that calculates the distribution probability of tested materials in each group based on the degree of gene contribution is more objective than other methods, but it classifies those tested materials in the groups with the highest distribution probabilities based on only the absolute values of distribution probabilities of the materials in each group, thus the resulting groups may not be correct for the tested materials that have similar distribution probabilities in the two groups with the highest probability. Mathematical clustering is based solely on the phenotypic values of multiple traits, and results from the analysis alone may also deviate from actual genetic relationship among the groups due to significant environmental effects and genotype by environment interactions. Thus a more comprehensive analytic approach is needed for effective classification of heterotic classes.

Previously, 128 Chinese foxtail millet accessions were analyzed using SSR markers, their molecular clusters and population structure were determined, and their pedigrees were analyzed to confirm the grouping results [9]. This study was conducted to classify 128 Chinese foxtail millet accessions into heterotic groups using mathematical clustering of the phenotypic data from an incomplete diallel cross experiment and to determine their heterotic patterns. 


\section{Materials and Methods}

\subsection{Plant Materials, Phenotypic Data Analysis}

The 128 foxteil millet accessions [9], DNA marker analysis, molecular clustering, and population structure analysis used in this study were described previously by Liu et al. (2011). All accessions were planted uniformly at the Experiment Station of Institute of Millet Crops, Hebei Academy of Agricultural and Forestry Sciences, Shijiajuang, China in 2008 and 2009. The experiment used a lattice square design with four replications. A total of 16 agronomic traits were recorded during the growing period including plant height, panicle length, panicle diameter, panicle-neck internode length, the first leaf length and width, the second leaf length and width, the third leaf length and width, percentage of harvested panicles, single panicle weight, grain weight per panicle, 1000-grain weight, percentage of grain weight over panicle weight, and total growth days. All the traits were measured according to the description criteria of millet germplasm resources [33]. Mean phenotypic values of each trait over four measurements were used for mathematical clustering using NTSYS-pc ver. 2.1 [34].

\subsection{Classification of Heterotic Classes}

Heterotic classes were definied by combined analyses of molecular clustering, population structure, mathematical clustering and pedigree clustering. If an accession had two highest, but distribute probability difference less than 0.1 between the groups in population structure analysis, the result from NJ clustering analysis was evaluated. If the result was consistent between the two analyses, the accession was kept in the original group as determined by the structure analysis; otherwise, pedigree analysis or mathematical clustering was used to determine its class in the case of accurate pedigree was not available.

\subsection{Establishment of Preponderance Heterotic Classes and Patterns}

After grouping adjustment, we selected 8 representative accessions (sterile lines or restorer lines) from all six newly formed heterotic classes and made 256 incomplete diallel crosses between the lines from different heterotic classes in 2010. In 2011, $\mathrm{F}_{1} \mathrm{~S}$ from all the 256 crosses were evaluated along with their 51 male parents and a control cultivar, Jigu 19, for yield and yield-related traits, including plant height, panicle length, panicle diameter, single panicle weight, panicle grain weight and 1000-grain weight, in an experiment using a lattice square design with fours replications. Transgressive heterosis and superstandard heterosis were calculated for all the traits, and used to determine heterotic patterns. If mean $\mathrm{F}_{1} \mathrm{~s}$ of cross combinations between two heterotic classes had yield transgressive heterosis $\geq 20 \%$ and superstandard heterosis $\geq 8 \%$, they were classified as a superior hetrotic patern; if mean $\mathrm{F}_{1} \mathrm{~S}$ of the combinations between two heterotic classes had yield transgressive heterosis between $5 \%$ to $20 \%$ and superstandard heterosis between $0 \%$ to $8 \%$, they were classified as an inferior hetrotic patern based on the following formula:

$$
\begin{aligned}
& \text { Transgressive heterosis }=\frac{(\text { Mean yield of hybrid combinations }- \text { mean yield of restorer }) \text { in two classes }}{\text { Mean yield of restorer in the two classes }} \times 100 \% \\
& \text { Superstandard Heterosis }=\frac{\text { Mean yield of hybrid combinations of two classes }- \text { yield of control }}{\text { Yield of the control cultivar }} \times 100 \%
\end{aligned}
$$

\section{Results}

\subsection{Classification of Heterotic Classes}

Based on the marker data, the 128 accessions were previously classified into six branches "B1, B2, B3, B4, B5, B6" based on phylogenetic analysis [9] and fu rther into six groups (G1, G2, G3, G4, G5, G6) based on their population structure [9]. In the population structure analysis, 13 accessions (V9, V15, V25, V32, V40, V42, V56, V 68, V77, V90, V98, V111 and V120) showed no significant difference in probabilities between the two highest probability groups with distribution probability difference less than 0.1 between the groups (Supplemental Table S1), thus the NJ clustering data were used to adjust the groupings of these accessions. Six accessions (V15, V32, V42, V68, V111, and V120) had consistent grouping results between the structure analysis and the NJ clustering, therefore, those accessions were kept in the group originally assigned by the structure analysis; 
whereas the NJ clustering gave different grouping results for other 7 accessions (V9, V25, V40, V56, V77, V90, and V98). Among the 7 accessions, only two (V98 and V25) had known pedigrees; V98 shared the same pedigree with V88 in G4 and V25 shared the same pedigree with G1 [9], thus V88 was moved to G4 and V25 remained in G1. The remaining five accessions had unknown pedigrees, thus were reclasssified based on mathematical clustering results (Figure 1). Because V77 from G1 was more close to V52 in G1, V9 and V56 were more close to V91 also in G1 in mathematical cluster tree, these three accessions were assigned to G1; similarly, V90 remained in the G3 where V106 were, and V40 were reassigned to the G6 where V65 were. After the adjustment, three accessions (V25, V77 and V90) remained in their original groups, and four (V9, V40, V56 and V98) were reassigned to different groups based on their pedigree or phenotypic similarity. Thus, the newly adjusted six groups were redesignated as six classes (C1 to C6 in Table 1). This result suggested that the grouping results from population structure analysis are more close to adjusted new classes than clustering analysis, thus population structure analysis provides more accurate grouping information.

To verify the rationality of the new classification method developed in this study, four accessions (V9, V40, V56, and V98) that were reassigned to different classes were crossed to five accessions that were selected from their coresponding groups and classes before and after they were adjusted. The results showed that the combining abilities for these combinations between individuals within the new classes was lower than that within original groups, indicating the genetic relationship among accessions within the newly formed classes was much closer than among accessions within original groups. This result indicates that the new classification method in this study is more reasonable (Table 2).

\subsection{Establishment of Heterotic Patterns}

The mean hybrid yield results from incomplete diallel cross experiment showed that the transgressive heterosis and superstandard heterosis were $30.30 \%$ and $10.26 \%$, respectively, for the patterns between accessions in C2 and C1, 33.16\% and 9.83\%, respectively, between C2 and C4, 38.04\% and 8.55\%, respectively, between C2 and C5, 27.50\% and 8.97\%, respectively, between C2 and C6, 21.05\% and 8.12\%, respectively, between C1 and 5, and $24.02 \%$ and $8.12 \%$, respectively, between C4 and C5.

Analysis of data for the five yield related traits (single panicle weight, panicle grain weight, panicle length, panicle diameter, and total growth days) collected from the incomplete dialele experiment identified six classes combinations that showed both strong transgressive heterosis and superstandard heterosis, including C2/C1, $\mathrm{C} 2 / \mathrm{C} 4, \mathrm{C} 2 / \mathrm{C} 5, \mathrm{C} 2 / \mathrm{C} 6, \mathrm{C} 1 / \mathrm{C} 5$ and C4/C5, thus, were defined as superior heterosis patterns to predict heterotic performance of their hybrids. Similarly, class combinations that have yield transgressive heterosis from $5 \%$ to $20 \%$ and superstandard heterosis from $0 \%$ to $8 \%$ is generally considered as an infereior heterotic pattern, and C1/C3, C1/C4, C1/C6 and C4/C6 met the criteria (Table 3).

\subsection{Genetic Distance of Preponderance Classes, Heterotic Patterns and Classes}

Based on the above analysis, C1, C2, C3, C4, C5 and C6 correspond to G1, G2, G3, G4, G5 and G6, respectively, with only adjustment of four lines. Therefore, the genetic distances among the original groups (G1 to G6) basically represents the genetic distances among corresponding newly formed classes (C1 to C6). The genetic distances among the newly formed classes determined by the incomplete diallel cross tests were basically identical to that of Nei's minimum distances and pairwise Fsts (Table 3 and [9]). In general, a heterotic pattern with the genetic distance larger than 0.17 between two heterotic classes in a heterotic pattern belonged to a superior heterotic pattern, and a heterotic pattern with genetic distances from 0.13 to 0.17 belonged to an infereior heterotic pattern. Based on this result, transgressive heterosis from " $24.2 \%$ " to "38.4\%" and superstandard heterosis from " $8.12 \%$ " to " $10.26 \%$ " can be considered superior heterosis patterns and transgressive heterosis from "7.33\%" to " $14.08 \%$ " and superstandard heterosis from " $0 \%$ " to " $4.70 \%$ " can be considered inferior heterotic patterns in this study. Thus heterotic classes and heterotic patterns established in this study are useful guildline for hybrid breeding using these germplasm.

\subsection{Heterosis Performance of Different Traits and Relationship between Transgressive Heterosis and Superstandard Heterosis among Traits}

Among different traits, heterosis between classes was not significant for 1000-grain weight and plant height 


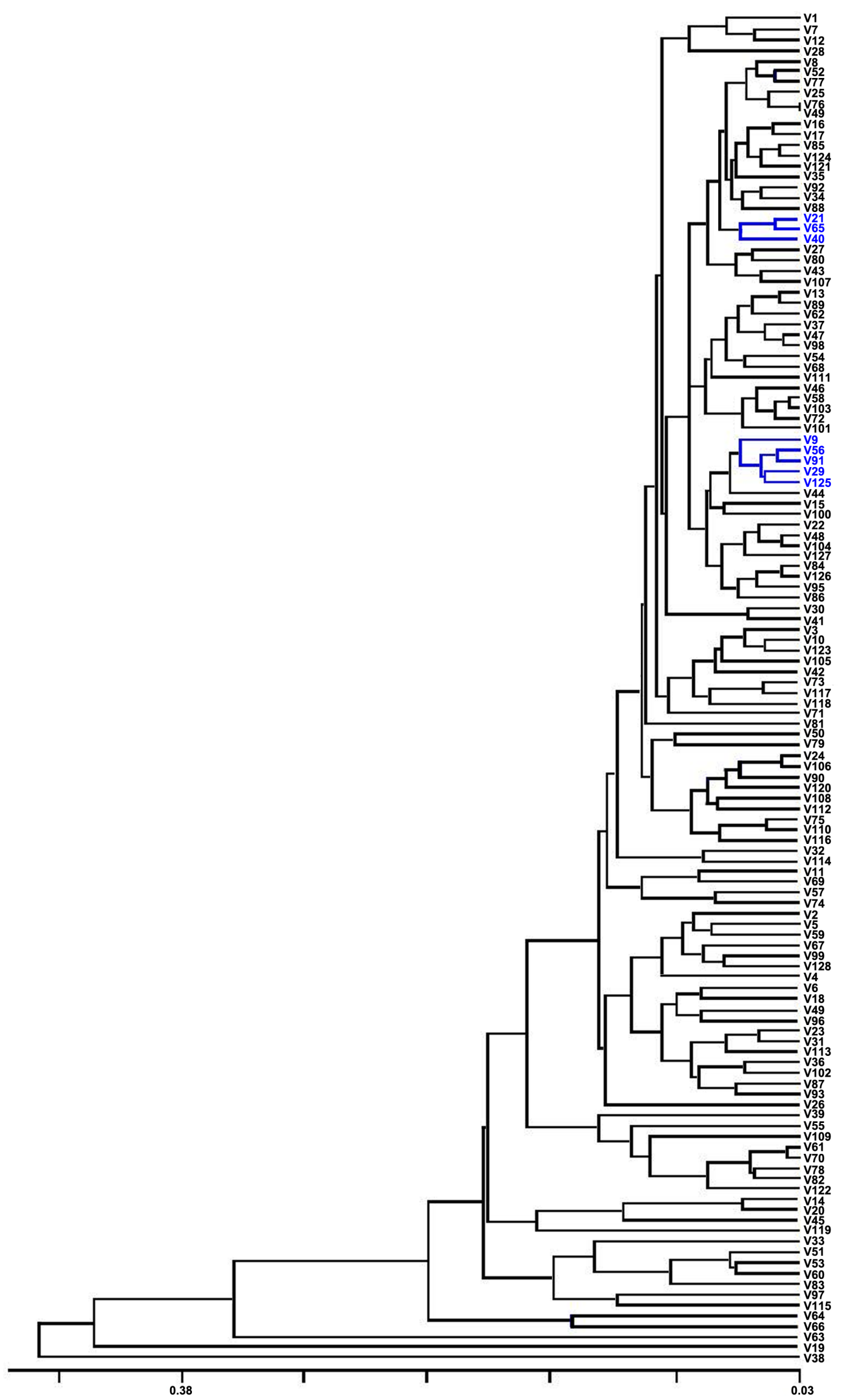

Figure 1. Mathematical cluster based on 128 accessions. 
Table 1. Comparison of accessions in original group (G) classified by structure analysis and newly formed classes (C) assigned by multiple analyses of 128 accessions.

\begin{tabular}{|c|c|c|}
\hline Newly formed class & Accessions & Original group \\
\hline \multirow{4}{*}{ C1 } & $\begin{array}{l}\text { V91, V48, V29, V27, V76, V84, V80, V86, V34, V100, V44, V52, V125, } \\
\text { V35, V47, V127, V70, V17, V115 }\end{array}$ & G1 \\
\hline & V25, V77, & G1 \\
\hline & V56 & G3 \\
\hline & V9 & G4 \\
\hline C2 & V73, V31, V36, V23, V114, V118, V117, V75, V110, V116, V32, V82, V50 & G2 \\
\hline \multirow[t]{2}{*}{ C3 } & $\begin{array}{l}\text { V67, V59, V45, V26, V10, V2, V1, V12, V5, V51, V53, V33, V128, V7, V28, } \\
\text { V3, V4, V6, V8, V24,V60, V64, V57, V120, V11, V54, V97, V20, V14, V83, } \\
\text { V112, V16, V119, V18, V106, V108, V93, V74, V79 }\end{array}$ & G3 \\
\hline & V90 & G3 \\
\hline \multirow{2}{*}{ C4 } & V88, V102, V13, V104, V89, V96, V87, V113, V109, V122, V61, V15, V111 & G4 \\
\hline & V98 & G5 \\
\hline C5 & V71, V101, V37, V81, V103, V58, V126, V92, V55 & G5 \\
\hline \multirow[t]{2}{*}{ C6 } & $\begin{array}{l}\text { V99, V85, V43, V30, V38, V62, V94, V105, V107, V78, V72, V121, V69, V22, } \\
\text { V63, V66, V19, V21, V124, V68, V95, V65, V41, V46, V49, V39, V42, V123 }\end{array}$ & G6 \\
\hline & V40 & G5 \\
\hline
\end{tabular}

Table 2. Combining ability between accessions V9, V40, V56, and V98 and selected accessions from both original groups and corresponding newly formed classes in which these four accessions located.

\begin{tabular}{ccc}
\hline Accessions & Original group $(\mathrm{G}) /$ newly formed class $(\mathrm{C})$ & General combining ability $\left(\mathrm{kg} / 4.5 \mathrm{~m}^{2}\right)$ \\
\hline \multirow{2}{*}{ V9 } & G4 & 2.34 \\
& C1 & 2.13 \\
V40 & G5 & 2.18 \\
& C6 & 2.09 \\
V56 & G3 & 2.29 \\
& C1 & 2.15 \\
V98 & G5 & 2.56 \\
& C4 & 2.01 \\
\hline
\end{tabular}

Table 3. Heterotic classes and heterotic patterns assigned based on the integreted analysis.

\begin{tabular}{|c|c|c|c|}
\hline Patterns & Transgressive heterosis (\%) & Superstandard heterosis (\%) & Type of pattern \\
\hline $\mathrm{C} 1, \mathrm{C} 2$ & 30.30 & 10.26 & \multirow{6}{*}{ Superior heterotic patterr } \\
\hline $\mathrm{C} 2, \mathrm{C} 4$ & 33.16 & 9.83 & \\
\hline C2, C5 & 38.04 & 8.55 & \\
\hline C2, C6 & 27.50 & 8.97 & \\
\hline C1, C5 & 21.05 & 8.12 & \\
\hline C4, C5 & 24.02 & 8.12 & \\
\hline C1, C3 & 14.08 & 0.43 & \multirow{4}{*}{ Inferior heterotic pattern } \\
\hline $\mathrm{C} 1, \mathrm{C} 4$ & 7.33 & 0.00 & \\
\hline C1, C6 & 8.41 & 4.70 & \\
\hline C4, C6 & 9.09 & 2.56 & \\
\hline C2, C3 & 8.33 & -16.67 & \multirow{4}{*}{ Non-heterotic pattern } \\
\hline C4, C3 & 0.50 & -14.1 & \\
\hline C3, C5 & 4.19 & -15.00 & \\
\hline C3, C6 & 5.31 & -6.84 & \\
\hline
\end{tabular}


(Table 4). In each heterotic pattern, hybrid performance of the two traits did not follow a certain trend and was not predictable, ranging from similar to either parent and close to midparent. The other five traits including yield, single panicle weight, panicle grain weight, panicle length and panicle diameter showed hybrid heterosis. In the

Table 4. Heterotic performance of yield-related traits evaluated in an incomplete-diallel-cross experiment using selected accessions from different heterotic patterns.

\begin{tabular}{|c|c|c|c|c|c|c|c|c|c|c|}
\hline Patterns & $\begin{array}{l}\text { Type of } \\
\text { Heterosis }\end{array}$ & Yield & $\begin{array}{l}\text { 1000-grain } \\
\text { weight }\end{array}$ & $\begin{array}{l}\text { Single } \\
\text { panicle } \\
\text { weight }\end{array}$ & $\begin{array}{l}\text { Panicle } \\
\text { grain } \\
\text { weight }\end{array}$ & $\begin{array}{c}\text { Panicle grain } \\
\text { weight/panicale } \\
\text { weight (\%) }\end{array}$ & Plant height & $\begin{array}{l}\text { Panicle } \\
\text { length }\end{array}$ & $\begin{array}{l}\text { Panicle } \\
\text { diameter }\end{array}$ & $\begin{array}{l}\text { Type of } \\
\text { patterns }\end{array}$ \\
\hline \multirow{2}{*}{ C1, C2 } & $\begin{array}{c}\text { Transgressive } \\
\text { (\%) }\end{array}$ & 30.30 & \multirow{2}{*}{ Low parent } & 29.24 & 21.40 & -5.95 & \multirow{2}{*}{ Tall parents } & 53.2 & 49.54 & \\
\hline & $\begin{array}{c}\text { Superstandard } \\
\text { (\%) }\end{array}$ & 10.26 & & 14.85 & 12.57 & -1.25 & & 37.52 & 41.06 & \\
\hline \multirow{2}{*}{$\mathrm{C} 2, \mathrm{C} 4$} & $\begin{array}{c}\text { Transgressive } \\
\text { (\%) }\end{array}$ & 33.16 & \multirow{2}{*}{ Low parent } & 26.29 & 14.16 & -10.23 & \multirow{2}{*}{ Tall parent } & 66.29 & 31.81 & \\
\hline & $\begin{array}{c}\text { Superstandard } \\
(\%)\end{array}$ & 9.83 & & 10.46 & 9.08 & -1.25 & & 43.22 & 35.90 & \\
\hline \multirow{2}{*}{ C2, C5 } & $\begin{array}{c}\text { Transgressive } \\
\text { (\%) }\end{array}$ & 38.04 & \multirow[b]{2}{*}{ Mid parents } & 32.73 & 29.89 & -2.41 & \multirow[b]{2}{*}{ Short parent } & 62.1 & 46.92 & \\
\hline & $\begin{array}{c}\text { Superstandard } \\
\text { (\%) }\end{array}$ & 8.55 & & 6.47 & 7.05 & 1.25 & & 40.09 & 37.84 & Strong \\
\hline \multirow{2}{*}{ C2, C6 } & $\begin{array}{c}\text { Transgressive } \\
\text { (\%) }\end{array}$ & 27.50 & \multirow[t]{2}{*}{ Mid parents } & 32.88 & 39.16 & -1.22 & \multirow{2}{*}{ Short parent } & 54.52 & 46.48 & $\begin{array}{l}\text { heterotic } \\
\text { patterns }\end{array}$ \\
\hline & $\begin{array}{c}\text { Superstandard } \\
\text { (\%) }\end{array}$ & 8.97 & & 14.53 & 15.33 & 1.25 & & 41.32 & 38.96 & \\
\hline \multirow{2}{*}{ C1, C5 } & $\begin{array}{c}\text { Transgressive } \\
\text { (\%) }\end{array}$ & 21.05 & \multirow{2}{*}{$\begin{array}{l}\text { Higher than } \\
\text { both parents }\end{array}$} & 38.65 & 39.47 & -2.38 & \multirow{2}{*}{ Short parent } & 60.62 & 47.19 & \\
\hline & $\begin{array}{l}\text { Superstandard } \\
\text { (\%) }\end{array}$ & 8.12 & & 8.47 & 10.94 & 2.50 & & 41.58 & 38.83 & \\
\hline \multirow{2}{*}{ C4, C5 } & $\begin{array}{c}\text { Transgressive } \\
\text { (\%) }\end{array}$ & 24.02 & \multirow{2}{*}{$\begin{array}{l}\text { Higher than } \\
\text { both parents }\end{array}$} & 39.14 & 33.20 & -3.57 & \multirow{2}{*}{ Mid-parent } & 62.29 & 38.66 & \\
\hline & $\begin{array}{l}\text { Superstandard } \\
\text { (\%) }\end{array}$ & 8.12 & & 9.28 & 9.70 & 1.25 & & 37.15 & 42.96 & \\
\hline \multirow[b]{2}{*}{ C1, C3 } & $\begin{array}{c}\text { Transgressive } \\
\text { (\%) }\end{array}$ & 14.08 & \multirow[b]{2}{*}{ High parents } & 19.97 & 18.30 & -1.20 & \multirow[b]{2}{*}{ Short parent } & 31.08 & 22.13 & \\
\hline & $\begin{array}{c}\text { Superstandard } \\
(\%)\end{array}$ & 0.43 & & 0.05 & 2.03 & 2.50 & & 19.05 & 12.57 & \\
\hline \multirow{2}{*}{ C1, C4 } & $\begin{array}{c}\text { Transgressive } \\
\text { (\%) }\end{array}$ & 7.33 & \multirow{2}{*}{$\begin{array}{l}\text { Higher than } \\
\text { both parents }\end{array}$} & 17.91 & 8.85 & -7.95 & \multirow{2}{*}{ Tall parent } & 30.82 & 15.49 & \\
\hline & $\begin{array}{c}\text { Superstandard } \\
\text { (\%) }\end{array}$ & 0.00 & & 2.81 & 3.95 & 1.25 & & 14.92 & 19.65 & Heterotic \\
\hline \multirow{2}{*}{ C1, C6 } & $\begin{array}{c}\text { Transgressive } \\
\text { (\%) }\end{array}$ & 8.41 & \multirow{2}{*}{$\begin{array}{l}\text { Higher than } \\
\text { both parents }\end{array}$} & 20.32 & 20.41 & 0.00 & \multirow{2}{*}{ Short parent } & 27.46 & 25.37 & patterns \\
\hline & $\begin{array}{l}\text { Superstandard } \\
\text { (\%) }\end{array}$ & 4.70 & & 1.31 & 3.10 & 2.50 & & 18.76 & 19.56 & \\
\hline \multirow{2}{*}{ C4, C6 } & $\begin{array}{c}\text { Transgressive } \\
\text { (\%) }\end{array}$ & 9.09 & \multirow{2}{*}{$\begin{array}{l}\text { Higher than } \\
\text { both parents }\end{array}$} & 20.09 & 17.79 & -2.38 & & 28.99 & 16.98 & \\
\hline & $\begin{array}{c}\text { Superstandard } \\
\text { (\%) }\end{array}$ & 2.56 & & 1.49 & 4.11 & 2.50 & Mid-parent & 15.51 & 21.82 & \\
\hline $\mathrm{C} 2 \mathrm{C3}$ & $\begin{array}{c}\text { Transgressive } \\
\text { (\%) }\end{array}$ & 8.33 & Lower than & 8.38 & 6.33 & & Shorter than & 17.81 & 15.13 & \\
\hline $4<, 4$ & $\begin{array}{l}\text { Superstandard } \\
\text { (\%) }\end{array}$ & -16.67 & both parents & -7.51 & -5.24 & 2.50 & both parent & 4.97 & 5.55 & \\
\hline $\mathrm{C} 4, \mathrm{C} 3$ & $\begin{array}{c}\text { Transgressive } \\
\text { (\%) }\end{array}$ & 0.50 & Lower than & 9.15 & 3.56 & -4.71 & Mid-parents & 17.4 & 4.14 & \\
\hline & $\begin{array}{l}\text { Superstandard } \\
\text { (\%) }\end{array}$ & -14.10 & both parents & -0.02 & -0.05 & 1.25 & & 2.36 & 5.13 & No heterotic \\
\hline$C_{3} C_{5}$ & $\begin{array}{c}\text { Transgressive } \\
\text { (\%) }\end{array}$ & 4.19 & Lower than & 1.09 & -1.63 & -3.66 & Shorter than & 7.85 & 1.29 & patterns \\
\hline U, & $\begin{array}{l}\text { Superstandard } \\
\text { (\%) }\end{array}$ & -15.00 & both parents & -24.34 & -25.31 & -1.25 & both parent & -0.06 & -0.07 & \\
\hline$C^{3} C_{6}$ & $\begin{array}{c}\text { Transgressive } \\
\text { (\%) }\end{array}$ & 5.31 & Lower than & -1.23 & -5.91 & -4.88 & Shorter than & 6.15 & 0.00 & \\
\hline C5, Co & $\begin{array}{c}\text { Superstandard } \\
\text { (\%) }\end{array}$ & -6.84 & both parents & -20.28 & -22.89 & -2.50 & both parent & -0.02 & -0.08 & \\
\hline
\end{tabular}


superior heterotic patterns, transgressive heterosis was strong and superstandard heterosis was obvious. In inferior heterotic patterns, transgressive heterosis existed but superstandard heterosis was weak or lacking. In those non-heterotic patterns, transgressive heterosis was weak or lacking, and superstandard heterosis generally showed disadvantages. In these superior heterotic patterns with strong heterosis in yield and yield-related traits, percentage of grain weight over panicale weight usually showed hybrid depression, which suggests that weaker heterosis for percentage of grain weight over panicale weight is associated with higher superior heterotic patterns for yield and yield-related components, thus increasing heterosis for percentage of grain weight over total panicale weight may improve yield potential.

Correlation analysis (Table 5) indicated that yield heterosis was significantly and positively correlated with single panicle weight, panicle grain weight, panicle length, and panicle diameter. These results indicate that transgressive heterosis and superstandard heterosis of yield are reliable parameters for classifying heterotic classes and establishing heterotic patterns.

\section{Discussion}

\subsection{Heterotic Classes Classification}

In the previous paper, population structure analysis was used to classify the groups based on the contribution of each accession to each group [9]. However, some accessions made similar contributions in the two highest probability groups with probability difference less than 0.1 between the groups. To validate the accuracy of classification based on structure analysis, the grouping result of NJ clustering analysis was compared. If NJ clustering groups the accessions in question to the same groups assigned by structure analysis, then we assume that the groups derived from the structure analysis are correct; otherwise, their groups need to be further adjusted according to either their pedigrees if available or mathematical clustering results if the pedigrees are not available. Using this integrated analysis method, some accessions in the six groups (G1 to G6) previously assigned by structure analysis were reasigned to different groups; thus the newly formed groups after adjustment were renamed as six heterotic classes (C1 to C6). Higher levels of heterosis were identified among the newly formed classes than within the classes in an incomplete diallel crosses experiment, which confirmed validity of newly formed classes and the new method used in this study. This work laid solid foundation for classification of heterotic classes and patterns for predicting the best cross combinations in heterotic hybrids breeding.

\subsection{Criteria for Determining Different Levels of Heterosis}

A new crop cultivar must be tested in regional trials at multiple locations and meet standard yield requirement before National Crop cultivar Evaluation and Approval Committee can approve it for release in China. The current national criterion is that a new foxtail millet hybrid cultivar has to increase yield for $8 \%$ over a conventional control. However, in research community, $15 \%$ of hybrid yield increase over a conventional control is considered as superior heterosis, thus becomes the breeding target for new hybrid cultivars. Because the conventional cultivar controls usually have better yield than the parents used in hybrid breeding programs, higher than $20 \%$ transgressive heterosis may be needed to reach required superstandard heterosis, which is equivalent to $8 \%$ or higher superstandard heterosis in superior heterotic patterns. Similarly, $5 \%$ to $20 \%$ of transgressive heterosis

Table 5. Correlation coefficients of transgressive heterosis and superstandard heterosis between traits.

\begin{tabular}{|c|c|c|c|c|c|c|}
\hline Traits & Yield & $\begin{array}{l}\text { Single panicle } \\
\text { weight }\end{array}$ & $\begin{array}{l}\text { Panicle grain } \\
\text { weight }\end{array}$ & $\begin{array}{c}\text { Percentage panicale grain } \\
\text { weightover panicale weight }\end{array}$ & $\begin{array}{l}\text { Panicle } \\
\text { length }\end{array}$ & $\begin{array}{l}\text { Panicle } \\
\text { diameter }\end{array}$ \\
\hline Yield & ----- & $0.883^{* *}$ & $0.821^{* *}$ & -0.474 & $0.886^{* *}$ & $0.724^{* *}$ \\
\hline Single panicle weight & $0.883^{* *}$ & ------ & $0.968^{* *}$ & -0.354 & $0.870^{* *}$ & $0.684^{* *}$ \\
\hline Panicle grain weight & $0.821^{* *}$ & $0.968^{* *}$ & ------ & -0.132 & $0.829^{* *}$ & $0.751^{* *}$ \\
\hline $\begin{array}{l}\text { Percentage panicale Grain } \\
\text { weight over Panicale weight }\end{array}$ & -0.474 & -0.354 & -0.132 & ------ & -0.365 & 0.000 \\
\hline Panicle length & $0.886^{* *}$ & $0.870^{* *}$ & $0.829^{* *}$ & -0.365 & ----- & $0.878^{* *}$ \\
\hline Panicle diameter & $0.724^{* *}$ & $0.684^{* *}$ & $0.751^{* *}$ & 0.000 & $0.878^{* *}$ & ------ \\
\hline
\end{tabular}

\footnotetext{
${ }^{* *}$ significant correlation.
} 
should be the actual standards for inferior heterotic patterns, which will translated into $0 \%-8 \%$ superstandard heterosis for inferior heterotic patterns.

\subsection{Establishment of Heterotic Classes and Utilization Patterns}

This study classified a core collection of breeding materials into different heterotic classes and heterotic patterns based on the combination of the genetic distance between classes, transgressive heterosis and superstandard heterosis of hybrids between the classes. The results suggested that the farther the genetic distance between two classes, the stronger the transgressive heterosis and superstandard heterosis of a hybrid, and the greater possibility to develop hybrids with superior heterosis when crosses are made between the two classes in a heterotic pattern.

The results show that the genetic distance between classes was consistent with the performance of transgressive heterosis and superstandard heterosis of hybrids in general, indicating that the methods for classifying hetorotic classess and heterotic patterns are reliable. According to the established heterotic patterns in this study, we crossed sterile lines "Gu 572A" from C4 to restorer lines "JK6-9" from C2 and obtained a strong heterotic hybrid "57269" (Z-L, Liu, unpublished data). Multiple yield trials showed that "57269" increased yield by $24.54 \%$ in an average over a standard control used in the yield trails. Successful development of strong heterotic hybrid " 57269 " based on predicted superior heterotic pattern suggests that the heterotic patterns established in this study is useful for predicting hybrid performance of these germplasm.

\subsection{Utilization of Heterotic Patterns in Hybrid Breeding}

Heterosis usually refers to both transgressive heterosis and superstandard heterosis [7] [35]-[37]. Transgressive heterosis represents the yield potential of a hybrid, where superstandard heterosis evaluates potential for a hybrid to be grown in farmer fields. Superior transgressive heterosis does not necessarily mean a superior superstandard heterosis. For example, transgressive heterosis and superstandard heterosis of $\mathrm{C} 2 / \mathrm{C} 4$ combinations were $33.16 \%$ and $9.83 \%$, respectively; transgressive heterosis of C2/C5 combination was 38.04\%, but superstandard heterosis was $8.55 \%$ only. This may be due to different yield levels of the parents. If the parents of a hybrid have similar yields to a control cultivar and their transgressive heterosis is high, and its sperstandard heterosis should also be high. Therefore, for these parents that have strong transgressive heterosis but not strong superstandard heterosis, parental yield potential should be improved before they can be used in developing strong heterotic hybrids.

To quickly develop strong heterotic hybrids, attention should be paid to these heterotic patterns that have strong transgressive heterosis and superstandard heterosis. For example, C2/C4 pattern had transgressive heterosis up to $33.16 \%$ and superstandard heterosis up to $9.83 \%$, and crosses among the accessions between the two classes will have a greater probability to develop hybrids with superstandard heterosis $>15 \%$. The hybrid " 57269 " was a good example. In the long run, we should use a combination of traditional cross breeding and recurrent selection to improve the parental yields of all heterotic clasess, especially the patterns whose transgressive heterosis is high but superstandard heterosis is low, such as in C2/C5 pattern.

\section{Conclusion}

In this study, a core collection of 128 accessions from China was grouped into six classes using combined analyses of population structure, pedigree, and clustering. The classification was conducted based mainly on molecular clustering of genotypic data, also considered the population structure and mathematical clustering using phenotypic data, and was finally validated through pedigree analysis. According to the transgressive and superstandard heterosis for grain yield, plant height, panicle length, panicle diameter, single panicle weight, grain weight per panicle, and 1000-grain weight collected from an incomplete-diallel-cross experiment, we identified six superior heterosis patterns (C2/C1, C2/C4, C2/C5, C2/C6, C1/C5 and C4/C5) and four inferior heterosis patterns (C1/C3, C1/C4, C1/C6 and C4/C6), and explored their potential applications in millet hybrid breeding. This study laid a foundation for effective use of foxtail millet heterosis in improving millet hybrid yield.

\section{Acknowledgements}

This research was partially supported by Hebei Province Millet Key Laboratory, National Foxtail Millet Im- 
provement Center, and The National Key Technology R\&D Program of China (2011BAD06B01).

\section{Competing Interests}

The authors declare that they have no competing interests.

\section{References}

[1] Hallauer, A.R. and Miranda, J.H. (1981) Quantitative Genetics in Maize Breeding. Iowa State University Press, Ames, 124-126.

[2] Zhang, T.Z. (2003) Crop Breeding. China Agricultural Science Press, Beijing.

[3] Wang, F. and Zhang, F.C. (1982) Study on Heterosis of Different Groups in Sorghum. Journal of Jilin Agricultural Sciences, 3, 6-12.

[4] Lu, Q.S., Sun, Y. and Hua, Z.T. (2001) Crop Heterosis. China Agricultural Science Press, Beijing.

[5] Fu, X.Q. and Gong, S.W. (1994) The Great Achievements of Hybrid Rice in Thirty Years and Its Further Developing Strategies in China. Hybrid Rice, 3-4, 17-21.

[6] Li, Y.M. (1997) Foxtail Millet Breeding. China Agricultural Science Press, Beijing.

[7] Liu, Z.L. (2010) Establish Method of Heterotic Group in Foxtail Millet and Its Research Progress. Journal of Hebei Agricultural Sciences, 14, 102-104.

[8] Liu, Z.L., Cheng, R.H., Zhang, F.L., Xia, X.Y., Shi, Z.H. and Hou, S.L. (2006) Analysis on Genetic Foundation and Study on Millet Variety and Its Pedigree in Boreali-Sinica Summer Millets Region. Acta Agriculturae Boreali-Sinica, 103-109.

[9] Liu, Z.L., Bai, G.H., Zhang, D.D., Zhu, C.S., Xia, X.Y., Cheng, R.H. and Shi, Z.G. (2011) Genetic Diversity and Population Structure of Elite Foxtail Millet [Setaria italica (L.) P. Beauv.] Germplasm in China. Crop Science, 51, 16551663. http://dx.doi.org/10.2135/cropsci2010.11.0643

[10] Jiang, Z.K., Liu, J.R., Wang, S.Y., Lu, Z.G., Yan, H.S., Liu, H.P., Liu, R.F. and Li, D.H. (2008) Analysis on Genetic Bases and Pedigree Evolution of Foxtail Millet Variety in Henan Province. Anhui Agriculture, 5, 124-127.

[11] Zhang, H.J. (2007) The Main Millet Variety Pedigree Analysis in Liaoning Province. Rain Fed Crops, 5, 343-344.

[12] Liu, Z.L., Cheng, R.H. and Li, X.Y. (1996) The Pedigree Analysis and Evaluation of North China Summer Millets. Crops, 5, 24.

[13] Li, Y., Jia, J.Z., Wang, Y.R. and Wu, S.Z. (1998) Intraspecific and Interspecific Variation in Setaria Revealed by RAPD Analysis. Genetic Resources and Crop Evolution, 45, 279-285. http://dx.doi.org/10.1023/A:1008600123509

[14] d’Ennequin, M.L.T., Panaud, O., Toupance, B. and Sarr, A. (2000) Assessment of Genetic Relationships between Setaria italica and Its Wild Relative S. Viridis Using AFLP Markers. Theoretical and Applied Genetics, 100, 1061-1066. http://dx.doi.org/10.1007/s001220051387

[15] Wang, J.Z., Hao, X.F., Wang, Y.Q., Wang, L.Y. and Sun, M.R. (2006) Study of Genetic Diversity of Millet Germplasm Resources by Molecular Markers. Biotechnology, 16, 10-14.

[16] Jia, X.P., Tan, X.J., Li, Y.X., Wang, T.Y. and Li, Y. (2009) A Study on the Genetic Diversity of Foxtail Millet Cultivars by SSR Markers. Acta Agriculturae Universitatis Jiangxiensis, 31, 633-638.

[17] Jia, X.P., Zhang, Z.B., Liu, Y.H., Zhang, C.W., Shi, Y.S., Song, Y.C., Wang, T.Y. and Li, Y. (2009b) Development and Genetic Mapping of SSR Markers in Foxtail Millet [Setaria italica (L.) P. Beauv.]. Theoretical and Applied Genetics, 118, 821-829. http://dx.doi.org/10.1007/s00122-008-0942-9

[18] Chen, Y.H., Wang, L.M. and Dai, J.R. (2000) Studies on the Heterotic Patterns between Tropical Subtropical and Chinese Temperate Germplasms in Maize. Acta Agronomica Sinica, 5, 557-564.

[19] Li, J.K., Zhang, L., Huang, Z.P., Zhang, L.Y. and Dai, O.H. (2002) Study on Making Soybean Cross Combination with M Type Male Steril Lines Heterosos of F1 and F2 Generation Yield of Hybrid Soybean and Its Utilization. Soybean Science, 21, 241-244.

[20] Li, X.H., Yuan, L.X., Li, X.H., Zhang, S.H., Li, M.S. and Li, W.H. (2003) Heterotic Grouping of 70 Maize Inbred Lines by SSR Markers. Scientia Agricultura Sinica, 6, 622-627.

[21] Liu, X.Z., Peng, Z.B., Fu, H., Li, L.C. and Huang, C.L. (1997) Heterotic Grouping of 15 Maize Inbreds with RAPD Markers. Scientia Agricultura Sinica, 3, 44-51.

[22] Yuan, L.X., Fu, J.H., Zhang, S.H., Liu, X.Z., Peng, Z.B., Li, X.H., Warburton, M. and Khairallah, M. (2001) Heterotic Grouping of Maize Inbred Lines Using RFLP and SSR Markers. Acta Agronomica Sinica, 2, 149-156.

[23] Yu, S.B., Li, J.X. and Xu, C.G. (1997) Importance of Epistasis as the Genetic Basis of Heterosis in an Elite Rice Hy- 
brid. Proceedings of the National Academy of Sciences of the United States of America, 94, 9226-9231. http://dx.doi.org/10.1073/pnas.94.17.9226

[24] Zhang, Q.F., Gao, Y.J., Saghui Marrof, M.A., Yang, S.H. and Li, J.X. (1995) Molecular Marker Heterozygosity and Hybrid Performance in Rice. Molecular Breeding, 1, 133-142. http://dx.doi.org/10.1007/BF01249698

[25] Zhang, Q.F., Zhang, Z.Q. and Yang, G.P. (1996) Molecular Marker Heterozygosity and Hybrid Performance in Indica and Japonica Rice. Theoretical and Applied Genetics, 93, 1218-1224. http://dx.doi.org/10.1007/BF00223453

[26] Yang, X. and Ouiros, C. (1993) Identification and Classification of Celery Cultivars with RAPD Marker. Theoretical and Applied Genetics, 85, 205-212.

[27] Xiao, J.H., Li, J.M. and Yuan, L.P. (1995) Dominance Is the Major Genetic Basis of Heterosis in Rice (Oryza sativa L.) as Revealed by QTLs Using Molecular Markers. Genetics, 140, 745-754.

[28] Luo, X.J., He, H.H., Fu, J.R., Ceng, X.R., Sun, J.L., Zhang, H.L. and Li, Z.C. (2006) Studies on Dividing Heterotic Groups in Indica Rice with SSR Molecular Markers. Hybrid Rice, 1, 61-64.

[29] Sun, Q.X., Huang, T.C. and Ni, Z.F. (1996) Study on Wheat Heterotic Group I. Genetic Diversity Revealed by Random Amplified Polymorphic DNA (RAPD) in Elite Wheat Cultivars. Journal of Agricultural Biotechnology, 2, $103-$ 110.

[30] Zeven, A.C. and Van Hiatam, T.J.L. (1992) Classification of Landraces and Improved Cultivars of Hexaploid Wheats (Triticum aesticum aestivum, T. compactum and T. spelta) Grown in USA and Described in 1992. Euphytica, 59, 33-47. http://dx.doi.org/10.1007/BF00025359

[31] Tinker, N.A., Fortin, M.G. and Mather, D.E. (1993) Random Amplified Polymorphic DNA and Pedigree Relationships in Spring Barley. Theoretical and Applied Genetics, 85, 976-984. http://dx.doi.org/10.1007/BF00215037

[32] Heun, M., Murphy, J.P. and Phillips, T.D. (1994) A Comparison of RAPD and Isozyme Analysis for Determining the Genetic Relationships among Avena sterilis Laccessions. Theoretical and Applied Genetics, 87, 689-696. http://dx.doi.org/10.1007/BF00222894

[33] Lu, P. (2006) Descriptors and Data Standard for Foxtail Millet [Setaria italica (L.) Beauv.]. China Agricultural Science and Technology Press, Beijing.

[34] Rohlf, F.J. (2000) NTSYS-PC. Numerical Taxonomy and Multivariate Analysis System. Version 2.10e. Department of Ecology and Evolution, State University of New York at Stony Brook, Stony Brook.

[35] Wei, Z.P., Zai, Y.J., Liu, S.R., Hong, X. and Jin, Z.J. (1985) Studies on the Heterosis and the Relationship between Parents and Offsprings of Hybrid Wheat with T. timopheevi Cytoplasm. Acta Agriculturae Universitatis Pekinensis, 11, 81-88.

[36] Li, M.S., Zhang, S.H., Li, X.H., Pan, G.T., Bai, L. and Peng, Z.B. (2002) Study on Heterotic Groups among Maize Inbred Lines Based on SCA. Scientia Agricultura Sinica, 6, 600-605.

[37] Yang, C.Q., Dang, Z.H., Zhang, J.P., Wang, L.M., Zhao, L., Xie, R.X. and Wang, B. (2009) Heterosis of Yield and Yield-Related Traits in the Oil Flax. Journal of Gansu Agricultural University, 44, 73-76. 


\section{Abbreviations}

G, group;

C, class;

$\mathrm{P}$, probability;

SSR, simple sequence repeat.

\section{Supplemental}

Table S1. 128 foxtail millet accessions used in this study (Liu et al., 2011).

\begin{tabular}{|c|c|c|c|c|c|c|c|}
\hline Entry & Name & G1 & G2 & G3 & G4 & G5 & G6 \\
\hline 1 & Tiegu8 & 0.006 & 0.006 & 0.852 & 0.049 & 0.033 & 0.054 \\
\hline 2 & Tiegu6 & 0.004 & 0.012 & 0.544 & 0.005 & 0.234 & 0.202 \\
\hline 3 & Tie487 & 0.007 & 0.011 & 0.937 & 0.008 & 0.01 & 0.027 \\
\hline 4 & Gonggu68 & 0.005 & 0.004 & 0.561 & 0.017 & 0.406 & 0.007 \\
\hline 5 & Tiegu14 & 0.006 & 0.006 & 0.87 & 0.008 & 0.041 & 0.07 \\
\hline 6 & Chao438 & 0.201 & 0.005 & 0.474 & 0.27 & 0.044 & 0.006 \\
\hline 7 & Jinzhougu 14 & 0.005 & 0.004 & 0.815 & 0.024 & 0.092 & 0.06 \\
\hline 8 & Tiegu7 & 0.007 & 0.008 & 0.581 & 0.31 & 0.07 & 0.025 \\
\hline 9 & Jinzhougu12 & 0.44 & 0.003 & 0.009 & 0.535 & 0.005 & 0.009 \\
\hline 10 & Tie8240 & 0.013 & 0.012 & 0.933 & 0.008 & 0.014 & 0.02 \\
\hline 11 & Xinggu88 & 0.025 & 0.222 & 0.527 & 0.013 & 0.167 & 0.046 \\
\hline 12 & Tiegu5 & 0.017 & 0.009 & 0.844 & 0.012 & 0.027 & 0.091 \\
\hline 13 & An2491 & 0.034 & 0.022 & 0.19 & 0.443 & 0.279 & 0.032 \\
\hline 14 & Datong29lv & 0.005 & 0.005 & 0.968 & 0.01 & 0.006 & 0.006 \\
\hline 15 & Shi206065 & 0.109 & 0.122 & 0.362 & 0.365 & 0.019 & 0.023 \\
\hline 16 & An9217 & 0.004 & 0.005 & 0.87 & 0.066 & 0.009 & 0.046 \\
\hline 17 & Bagu214 & 0.765 & 0.01 & 0.032 & 0.038 & 0.081 & 0.074 \\
\hline 18 & Jigu30 & 0.016 & 0.037 & 0.682 & 0.041 & 0.041 & 0.183 \\
\hline 19 & Jigu26 & 0.034 & 0.008 & 0.199 & 0.006 & 0.007 & 0.747 \\
\hline 20 & Datong29zi & 0.008 & 0.006 & 0.971 & 0.005 & 0.005 & 0.006 \\
\hline 21 & Shi206058 & 0.065 & 0.11 & 0.072 & 0.007 & 0.011 & 0.734 \\
\hline 22 & Shi207226 & 0.017 & 0.018 & 0.034 & 0.051 & 0.022 & 0.859 \\
\hline 23 & Changgao146A & 0.005 & 0.858 & 0.009 & 0.011 & 0.005 & 0.113 \\
\hline 24 & Shi207191 & 0.068 & 0.008 & 0.472 & 0.331 & 0.054 & 0.067 \\
\hline 25 & Jigu25 & 0.343 & 0.043 & 0.312 & 0.177 & 0.035 & 0.09 \\
\hline 26 & Chaogu13 & 0.014 & 0.024 & 0.909 & 0.009 & 0.013 & 0.031 \\
\hline 27 & K359 & 0.585 & 0.005 & 0.004 & 0.004 & 0.395 & 0.006 \\
\hline 28 & Tiedalihuang & 0.007 & 0.01 & 0.795 & 0.006 & 0.053 & 0.129 \\
\hline 29 & L70 & 0.954 & 0.003 & 0.01 & 0.004 & 0.007 & 0.022 \\
\hline 30 & K523 & 0.347 & 0.032 & 0.095 & 0.004 & 0.03 & 0.493 \\
\hline
\end{tabular}




\section{Continued}

\begin{tabular}{|c|c|c|c|c|c|c|c|}
\hline 31 & Changgao117A & 0.004 & 0.908 & 0.056 & 0.018 & 0.004 & 0.011 \\
\hline 32 & Yangu No.12 & 0.009 & 0.526 & 0.437 & 0.01 & 0.014 & 0.005 \\
\hline 33 & Gonggu70 & 0.011 & 0.007 & 0.881 & 0.023 & 0.018 & 0.06 \\
\hline 34 & Jigu29 & 0.761 & 0.004 & 0.015 & 0.018 & 0.181 & 0.021 \\
\hline 35 & S80 & 0.505 & 0.005 & 0.006 & 0.005 & 0.305 & 0.174 \\
\hline 36 & Changgao229A & 0.007 & 0.875 & 0.019 & 0.024 & 0.006 & 0.07 \\
\hline 37 & Jinangu13 & 0.067 & 0.009 & 0.007 & 0.003 & 0.784 & 0.129 \\
\hline 38 & Cang156 & 0.044 & 0.004 & 0.005 & 0.02 & 0.01 & 0.918 \\
\hline 39 & Jinfen1A & 0.007 & 0.339 & 0.052 & 0.007 & 0.004 & 0.59 \\
\hline 40 & Fu532 & 0.013 & 0.005 & 0.125 & 0.31 & 0.407 & 0.14 \\
\hline 41 & C445 & 0.013 & 0.004 & 0.004 & 0.023 & 0.015 & 0.941 \\
\hline 42 & Chaogu12 & 0.013 & 0.426 & 0.054 & 0.006 & 0.004 & 0.498 \\
\hline 43 & C208 & 0.219 & 0.004 & 0.021 & 0.009 & 0.071 & 0.676 \\
\hline 44 & C138 & 0.556 & 0.005 & 0.01 & 0.023 & 0.008 & 0.398 \\
\hline 45 & Chigu No.4 & 0.01 & 0.023 & 0.948 & 0.004 & 0.005 & 0.01 \\
\hline 46 & Shi02399 & 0.056 & 0.007 & 0.141 & 0.004 & 0.229 & 0.562 \\
\hline 47 & Y61 & 0.564 & 0.025 & 0.024 & 0.179 & 0.197 & 0.011 \\
\hline 48 & Cang344 & 0.537 & 0.005 & 0.009 & 0.416 & 0.026 & 0.007 \\
\hline 49 & Jinfen3A & 0.006 & 0.351 & 0.034 & 0.007 & 0.004 & 0.597 \\
\hline 50 & Jin15A & 0.005 & 0.64 & 0.342 & 0.004 & 0.004 & 0.004 \\
\hline 51 & Datong28 & 0.007 & 0.105 & 0.876 & 0.004 & 0.003 & 0.005 \\
\hline 52 & Zheng9188 & 0.754 & 0.004 & 0.122 & 0.004 & 0.09 & 0.025 \\
\hline 53 & Datong14 & 0.338 & 0.009 & 0.634 & 0.005 & 0.006 & 0.008 \\
\hline 54 & Zhengkang2 & 0.024 & 0.07 & 0.885 & 0.005 & 0.007 & 0.009 \\
\hline 55 & Dungu1 & 0.068 & 0.003 & 0.004 & 0.007 & 0.899 & 0.019 \\
\hline 56 & Yugu No.6 & 0.166 & 0.014 & 0.328 & 0.293 & 0.147 & 0.052 \\
\hline 57 & Datong30 & 0.047 & 0.011 & 0.905 & 0.006 & 0.006 & 0.026 \\
\hline 58 & Chenggu12 & 0.082 & 0.01 & 0.11 & 0.003 & 0.613 & 0.181 \\
\hline 59 & Chigu No.10 & 0.013 & 0.066 & 0.907 & 0.003 & 0.004 & 0.007 \\
\hline 60 & Datong27 & 0.007 & 0.01 & 0.972 & 0.004 & 0.004 & 0.004 \\
\hline 61 & Gu3A & 0.168 & 0.05 & 0.015 & 0.633 & 0.005 & 0.129 \\
\hline 62 & An4852 & 0.26 & 0.005 & 0.023 & 0.016 & 0.017 & 0.679 \\
\hline 63 & Shi207286 & 0.009 & 0.016 & 0.011 & 0.071 & 0.015 & 0.879 \\
\hline 64 & Shi02530 & 0.094 & 0.007 & 0.525 & 0.079 & 0.237 & 0.059 \\
\hline 65 & Shi207393 & 0.02 & 0.033 & 0.02 & 0.106 & 0.243 & 0.579 \\
\hline 66 & Shi207382 & 0.165 & 0.027 & 0.033 & 0.023 & 0.164 & 0.587 \\
\hline 67 & Chigu8 & 0.006 & 0.034 & 0.925 & 0.007 & 0.016 & 0.012 \\
\hline
\end{tabular}




\section{Continued}

\begin{tabular}{|c|c|c|c|c|c|c|c|}
\hline 68 & Shi98700 & 0.135 & 0.018 & 0.368 & 0.035 & 0.012 & 0.432 \\
\hline 69 & Shi02521 & 0.106 & 0.186 & 0.119 & 0.021 & 0.011 & 0.556 \\
\hline 70 & Gu6A & 0.574 & 0.036 & 0.008 & 0.155 & 0.171 & 0.057 \\
\hline 71 & Shi97672 & 0.028 & 0.015 & 0.26 & 0.005 & 0.441 & 0.251 \\
\hline 72 & Shi98622 & 0.018 & 0.006 & 0.141 & 0.032 & 0.342 & 0.462 \\
\hline 73 & Jingu No.16 & 0.007 & 0.924 & 0.016 & 0.009 & 0.039 & 0.006 \\
\hline 74 & Chaolv-1 & 0.007 & 0.026 & 0.95 & 0.006 & 0.005 & 0.006 \\
\hline 75 & Changgu No.1 & 0.115 & 0.665 & 0.082 & 0.006 & 0.005 & 0.126 \\
\hline 76 & K546 & 0.961 & 0.005 & 0.014 & 0.005 & 0.007 & 0.009 \\
\hline 77 & Gu10A & 0.481 & 0.006 & 0.006 & 0.007 & 0.05 & 0.451 \\
\hline 78 & Richaogu & 0.017 & 0.015 & 0.407 & 0.004 & 0.017 & 0.54 \\
\hline 79 & Meiguodatou & 0.004 & 0.007 & 0.795 & 0.004 & 0.167 & 0.023 \\
\hline 80 & K660 & 0.506 & 0.006 & 0.005 & 0.337 & 0.134 & 0.012 \\
\hline 81 & K1011 & 0.004 & 0.005 & 0.244 & 0.248 & 0.494 & 0.004 \\
\hline 82 & Gu11A & 0.005 & 0.711 & 0.034 & 0.011 & 0.23 & 0.008 \\
\hline 83 & Bagu214-2 & 0.006 & 0.009 & 0.972 & 0.006 & 0.004 & 0.003 \\
\hline 84 & K1130 & 0.893 & 0.01 & 0.015 & 0.039 & 0.032 & 0.011 \\
\hline 85 & Jigu19 & 0.014 & 0.006 & 0.021 & 0.005 & 0.021 & 0.933 \\
\hline 86 & Xiaoxiangmi & 0.63 & 0.007 & 0.015 & 0.33 & 0.011 & 0.007 \\
\hline 87 & Gu38A & 0.038 & 0.024 & 0.055 & 0.683 & 0.08 & 0.121 \\
\hline 88 & Shi06-439 & 0.203 & 0.01 & 0.27 & 0.495 & 0.01 & 0.011 \\
\hline 89 & Gufeng2 & 0.009 & 0.005 & 0.024 & 0.697 & 0.124 & 0.14 \\
\hline 90 & Gu57A & 0.048 & 0.011 & 0.434 & 0.353 & 0.143 & 0.01 \\
\hline 91 & Shi181-5 & 0.562 & 0.003 & 0.009 & 0.401 & 0.006 & 0.019 \\
\hline 92 & Jigu21 & 0.051 & 0.004 & 0.004 & 0.011 & 0.92 & 0.01 \\
\hline 93 & Gu65A & 0.06 & 0.081 & 0.795 & 0.02 & 0.013 & 0.031 \\
\hline 94 & Jigu22 & 0.036 & 0.035 & 0.02 & 0.186 & 0.025 & 0.698 \\
\hline 95 & Jigu20 & 0.005 & 0.005 & 0.111 & 0.039 & 0.241 & 0.598 \\
\hline 96 & Gu66A & 0.022 & 0.014 & 0.02 & 0.925 & 0.005 & 0.015 \\
\hline 97 & Yangu No.13 & 0.004 & 0.334 & 0.632 & 0.01 & 0.016 & 0.005 \\
\hline 98 & Shi06-766 & 0.329 & 0.038 & 0.091 & 0.065 & 0.378 & 0.099 \\
\hline 99 & Jigu No.12 & 0.01 & 0.01 & 0.232 & 0.011 & 0.008 & 0.73 \\
\hline 100 & Bao182 & 0.582 & 0.04 & 0.181 & 0.127 & 0.062 & 0.007 \\
\hline 101 & Jinangu11 & 0.18 & 0.012 & 0.041 & 0.063 & 0.693 & 0.011 \\
\hline 102 & Jinangu12 & 0.374 & 0.006 & 0.015 & 0.492 & 0.081 & 0.033 \\
\hline 103 & Chaogu15 & 0.005 & 0.011 & 0.133 & 0.005 & 0.832 & 0.014 \\
\hline 104 & Lugu No.10 & 0.005 & 0.004 & 0.099 & 0.729 & 0.01 & 0.153 \\
\hline
\end{tabular}




\begin{tabular}{|c|c|c|c|c|c|c|c|}
\hline \multicolumn{8}{|c|}{ Continued } \\
\hline 105 & Ji9409 & 0.006 & 0.006 & 0.293 & 0.062 & 0.039 & 0.594 \\
\hline 106 & Jigu27 & 0.003 & 0.006 & 0.98 & 0.005 & 0.003 & 0.003 \\
\hline 107 & Ji9403 & 0.14 & 0.012 & 0.161 & 0.125 & 0.01 & 0.552 \\
\hline 108 & Heng968 & 0.006 & 0.009 & 0.726 & 0.01 & 0.006 & 0.243 \\
\hline 109 & Gu83A & 0.21 & 0.025 & 0.094 & 0.636 & 0.03 & 0.006 \\
\hline 110 & Taixuan4 & 0.012 & 0.578 & 0.22 & 0.127 & 0.017 & 0.046 \\
\hline 111 & Chaogu14 & 0.04 & 0.009 & 0.302 & 0.334 & 0.171 & 0.144 \\
\hline 112 & Jingu No.29 & 0.004 & 0.285 & 0.527 & 0.164 & 0.011 & 0.009 \\
\hline 113 & Gu95A & 0.156 & 0.007 & 0.104 & 0.703 & 0.014 & 0.017 \\
\hline 114 & Jingu No.21 & 0.012 & 0.853 & 0.109 & 0.004 & 0.008 & 0.014 \\
\hline 115 & Taixuan2 & 0.498 & 0.071 & 0.322 & 0.008 & 0.007 & 0.093 \\
\hline 116 & Taixuan5 & 0.081 & 0.512 & 0.345 & 0.012 & 0.039 & 0.01 \\
\hline 117 & Jingu No.35 & 0.078 & 0.755 & 0.149 & 0.004 & 0.008 & 0.005 \\
\hline 118 & Changnong35 & 0.006 & 0.89 & 0.089 & 0.005 & 0.006 & 0.005 \\
\hline 119 & Jigu28 & 0.031 & 0.048 & 0.707 & 0.023 & 0.142 & 0.049 \\
\hline 120 & Changnong36 & 0.01 & 0.336 & 0.428 & 0.168 & 0.018 & 0.041 \\
\hline 121 & Jigu24 & 0.023 & 0.005 & 0.005 & 0.021 & 0.057 & 0.888 \\
\hline 122 & ZA1 & 0.31 & 0.034 & 0.028 & 0.615 & 0.005 & 0.008 \\
\hline 123 & C178 & 0.249 & 0.005 & 0.214 & 0.036 & 0.012 & 0.484 \\
\hline 124 & Shi202242 & 0.113 & 0.018 & 0.032 & 0.042 & 0.011 & 0.784 \\
\hline 125 & An2367 & 0.536 & 0.064 & 0.028 & 0.027 & 0.324 & 0.02 \\
\hline 126 & 203184zao & 0.178 & 0.005 & 0.032 & 0.004 & 0.519 & 0.262 \\
\hline 127 & C164 & 0.728 & 0.011 & 0.025 & 0.178 & 0.045 & 0.013 \\
\hline 128 & Gonggu65 & 0.006 & 0.006 & 0.875 & 0.011 & 0.008 & 0.095 \\
\hline
\end{tabular}


Scientific Research Publishing (SCIRP) is one of the largest Open Access journal publishers. It is currently publishing more than 200 open access, online, peer-reviewed journals covering a wide range of academic disciplines. SCIRP serves the worldwide academic communities and contributes to the progress and application of science with its publication.

Other selected journals from SCIRP are listed as below. Submit your manuscript to us via either submit@scirp.org or Online Submission Portal.
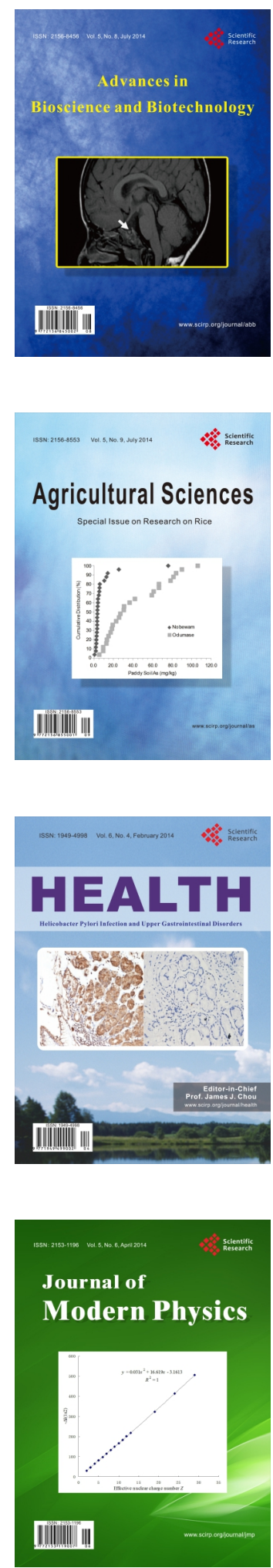
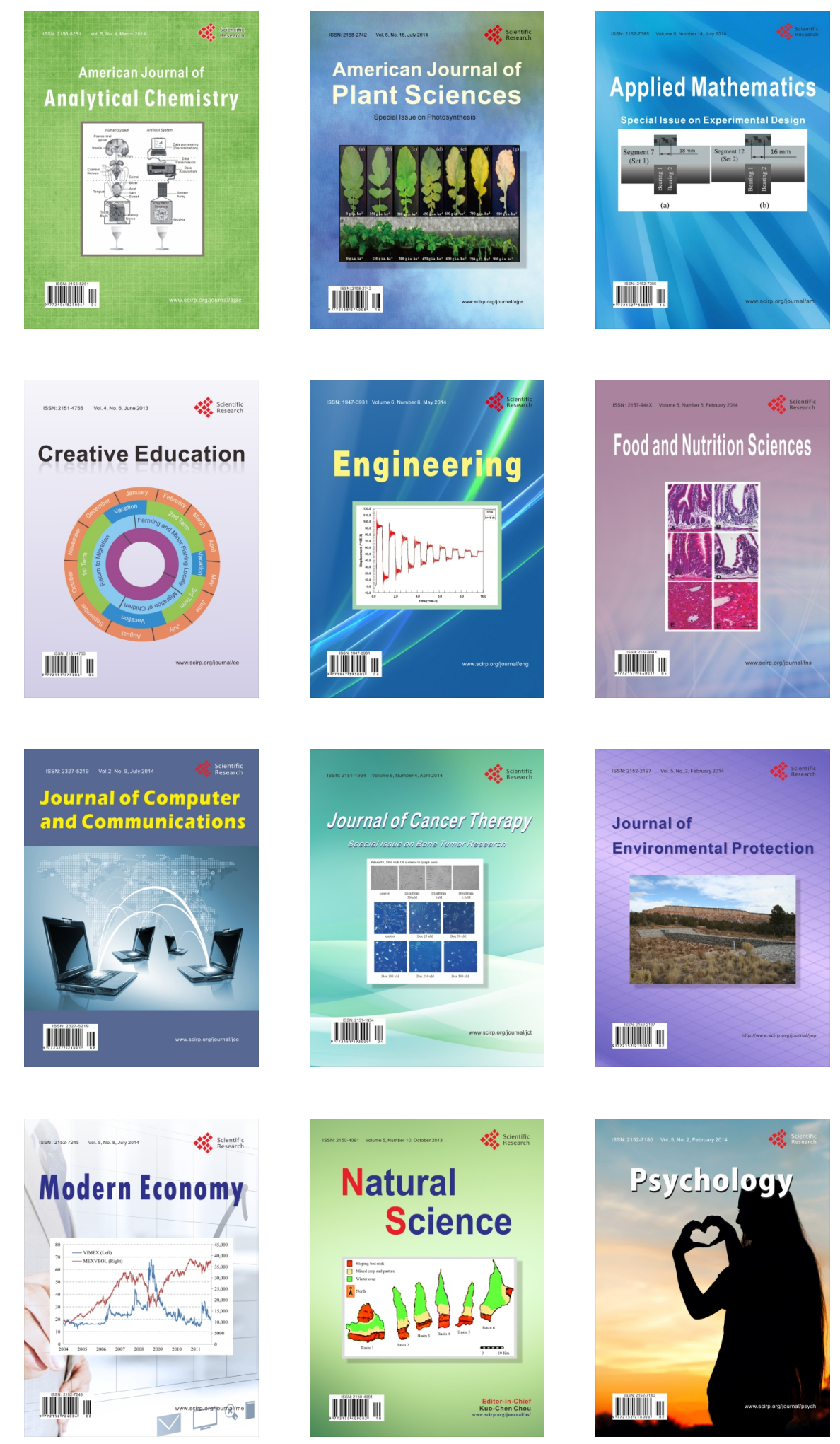